\title{
A Space for Every Student: Assessing the Utility of a Family Friendly Study Room in a University Library
}

Tyler Graff

Brigham Young University, tygraff@gmail.com

Bob Ridge

Brigham Young University, robert_ridge@byu.edu

Holt Zaugg

Brigham Young University, holt_zaugg@byu.edu

Follow this and additional works at: https://scholarsarchive.byu.edu/facpub

Original Publication Citation

Journal of Library Administration

\section{BYU ScholarsArchive Citation}

Graff, Tyler; Ridge, Bob; and Zaugg, Holt, "A Space for Every Student: Assessing the Utility of a Family Friendly Study Room in a University Library" (2019). Faculty Publications. 4172.

https://scholarsarchive.byu.edu/facpub/4172 


\section{A Space for Every Student: Assessing the Utility of a Family Friendly Study Room in a University Library}

\section{Tyler C. Graff, Robert D. Ridge \& Holt Zaugg}

To cite this article: Tyler C. Graff, Robert D. Ridge \& Holt Zaugg (2019): A Space for Every Student: Assessing the Utility of a Family Friendly Study Room in a University Library, Journal of Library Administration

To link to this article: https://doi.org/10.1080/01930826.2019.1626650

曲制 Published online: 21 Jun 2019.

Submit your article to this journal $₫$

View Crossmark data $₫$ 


\title{
A Space for Every Student: Assessing the Utility of a Family Friendly Study Room in a University Library
}

\author{
TYLER C. GRAFF \\ Graduate Research Fellow, Department of Psychology, Brigham Young University, Provo, \\ $U T, U S A$ \\ ROBERT D. RIDGE \\ Associate Professor of Psychology, Department of Psychology, Brigham Young University, \\ Provo, UT, USA
}

HOLT ZAUGG

Assessment Librarian, Brigham Young University, Provo, UT, USA

\begin{abstract}
Students currently in and returning to college are increasingly likely to have children. The demands of academic and family life can conflict, making it difficult for studentparents to navigate both. Brigham Young University recently built a Family Friendly Study Room in the university library to provide a place for student-parents to care for their children while engaging in academic work. This study assessed the impact of the FFSR on patrons. Results show that the space is bighly valued and offers both academic and relationship benefits. Moreover, students' suggestions provide important feedback for future improvements. Recommendations for creating family-friendly spaces in university libraries are discussed.
\end{abstract}

KEYWORDS university library, family room, evaluation, student-parents, children

(C) The Author(s)

Address correspondence to Tyler C. Graff, Graduate Research Fellow, Department of Psychology, Brigham Young University, Provo, UT 84602, USA. E-mail: tygraff@byu.edu 


\section{INTRODUCTION}

A recently divorced mother with twin 18-month old girls returns to the university full-time while working part-time on campus. A library employee returns to work one week after having her third child. A young married couple with three small children is trying to complete their undergraduate degrees. A married mother of two small children returns to the university to complete work on her doctoral degree. A dad with three children who works full-time returns to school to improve his employment opportunities. What do all of these people have in common (Haymond, 2018)? The commonality is a space on campus to support them and their family - somewhere that feels like home, where they can spend time as a family and continue to pursue their academic studies. This is the motivation behind the creation of family friendly rooms within academic libraries.

\section{LITERATURE REVIEW}

The issue of how and where children fit into academic library settings is decades old (Anderson, Armentrout, \& Beronä, 1994). Most instances seek to balance the needs of parents, who need to interact with their children, with the needs of other library patrons, who seek a quiet place for study. However, changing demographics of library patrons foretell the likelihood and need for children to accompany their parents to academic libraries. Anderson et al. (1994) report that from 1980 to 1992 the number of university students under 25 -years old rose by only $3 \%$. However, university students over 25 -years old rose by $34 \%$. Although not all older students will have children, there will be more students over 25 who do have children than those under 25.

More recent statistics support this assertion that more college students have dependent children. Adam (2014) indicates that 25\% of college students have dependent children, a $2 \%$ increase from 2008. However, if the data are disaggregated by race, the percent of students with dependent children ranges from almost $32 \%$ (Latina students) to $47 \%$ (African American female students). Other studies support the 20-25\% rate of students with dependent children on national levels (Demeules \& Hamer, 2013) and for specific universities (Godfrey et al., 2017; Petit, 2014). The rates of students with dependent children argue for additional support as they proceed through their education.

Institutions have adopted a variety of approaches to address this need. Moreau (2016) reviewed the policies regarding student-parents at ten 
universities in England and Wales. This study revealed three categories of university policy:

1. Universal or Careblind policies that had minimal or no policy regarding student-parents, with little or no support.

2. Targeted policies which had some provision in specific instances (e.g., nurseries) for student-parents.

3. Mainstreaming policies that seek to integrate parents and their children into university life.

The first two categories assumed a position that children should be rarely, if ever, seen or heard on campus. Universities were responsible solely for their students. The last group of university policies made children welcome in all but dangerous areas (e.g., research labs), including lectures and seminars (with lecturer approval). They sought to make a welcoming space for student-parents and their children.

Other institutions have adopted a more hands-on approach that ranges from literacy, reading and storytelling programs for the children of student-parents (Tvaruzka, 2017) to programs offering financial and counseling support to student-parents (Demeules \& Hamer, 2013). In some cases, academic libraries were approached to create a family friendly space that would meet the needs of student-parents and their children (Godfrey et al., 2017; McCoy, 2013). These spaces typically have amenities for children to play and interact while parents work on school assignments. They often allow for food and noise associated with children, but preserve the quiet spaces elsewhere in the library. They range from spaces with access restricted to student-parents only (e.g., through reservation or ID card swipe access) to those that are open-access to all with preference for student-parents and their children. The end result is a proactive effort that meets the needs of a growing segment of university students. It is a way to build trust with students and make them feel wanted and welcomed as they pursue their education.

\section{STERLING FAMILY FRIENDLY ROOM}

In 2015, the Lee Library at Brigham Young University (BYU) began the design and development of a family friendly space for student-parents. Following observations of family programs at local public libraries and reviews of family rooms at Utah Valley University and the University of Utah, a Family Friendly Study Room (FFSR) was designed and built on the 
main floor of the library and opened in September, 2017. It provides a variety of study spaces for student-parents, toys and play spaces for children, and practical family spaces (e.g., family bathrooms and lactation areas for nursing mothers; see Figure 1).

Although assessments assisted the design and development of the family friendly space, no subsequent study has been conducted to determine the degree to which the family friendly space is helping students with family and academic needs. This effort is an initial assessment of the FFSR. It seeks to better understand if the designed spaces are functioning as intended, what other amenities or changes would improve the family experience in the room, and the impact the room has had on student-parents.

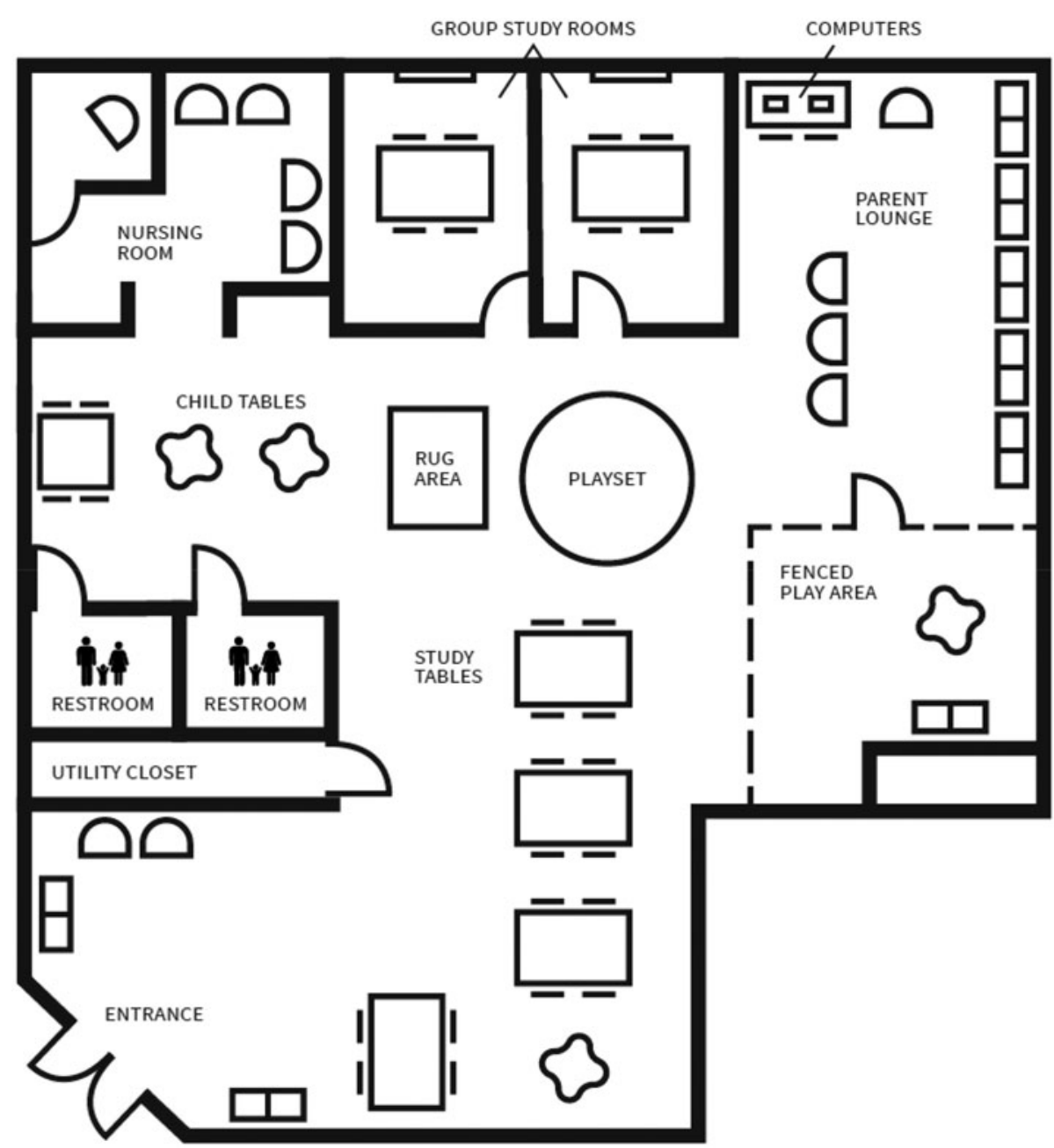

FIGURE 1 Schematic drawing of the FFSR. 


\section{MATERIALS AND METHODS}

This project used convenience and snowball sampling methods to recruit participation. Posters were placed in various locations around the FFSR (e.g., on the walls and on study tables) announcing the study and inviting participation. Each poster contained researcher contact information and a QR code linking participants to the survey. In addition to these posters, at various times throughout the day and over the course of three weeks, a research assistant approached potential participants who were currently in the FFSR and asked if they would be willing to take a survey regarding the space. If the participant agreed, the researcher emailed a survey link to the participant. Additionally, participants were asked to forward the link to any others they knew who used the room. As an incentive to participate, at the end of the survey participants were able to opt into a drawing to receive one of four U.S. $\$ 20$ cash awards. This study was approved by the Brigham Young University Institutional Review Board.

\section{Participants}

Ninety-eight participants responded to the survey. Six of the responses, however, were unusable due to incomplete data. Thus, the total sample size for this project was 92 (59\% female). Only twelve participants did not have at least one child. Those who did not have children were nevertheless using the room for family-related reasons (e.g., study group where one member has a child, person is babysitting for a friend who is in class) and were included in the analysis. Demographic information is located in Table 1.

\section{Measures}

An online survey hosted by Qualtrics was created to assess how participants discovered the room, their satisfaction with the space, and any recommendations they might have for improvements. Questions included both closed (quantitative) and open-ended (qualitative) types. A demographic questionnaire assessed variables including participant age, child information, gender, marital status, and educational information (see the Appendix for the full survey).

Discovery, use, and recommendations. This measure consisted of ten questions regarding how participants discovered the FFSR, how they were using the room, as well as their recommendations for how to improve their experience with the room. Examples of open-ended items included, "How did you find out about the Family Friendly Study Room? 
TABLE 1 Demographic information.

\begin{tabular}{lrr}
\hline & $N$ & $\%$ \\
\hline Total participants & 92 & 100 \\
Female & 54 & 59 \\
Married : Yes & 78 & 85 \\
Age in years & 2 & 2 \\
Under 20 & 79 & 86 \\
$20-29$ & 9 & 10 \\
Over 29 & 89 & 97 \\
Current student or spouse of student & & \\
School status & 2 & 4 \\
Freshmen & 4 & 17 \\
Sophomore & 16 & 27 \\
Junior & 25 & 16 \\
Senior & 15 & 30 \\
Super senior (5 or more years) & 28 & 85 \\
Other: graduate, visitor, faculty & 78 & \\
Total participants with children & & 13 \\
Number of children & 12 & 61 \\
None & 56 & 18 \\
1 & 17 & 5 \\
2 & 5 & \\
More than 2 & & 54 \\
Age of children in years & 50 & 35 \\
Under 1 & 32 & 25 \\
1-2 & 23 & 4 \\
2-8 & 4 & \\
Over 8 & & \\
\hline Pench & & \\
\hline
\end{tabular}

Percentages are rounded up.

(please be specific)", "How often do you currently use the Family Friendly Study Room?", and "What about the Family Friendly Study Room could be improved to help address your needs better?".

Satisfaction and quality. To measure participant's satisfaction with the FFSR, seven individual questions were used. The satisfaction questions were specific to the FFSR and included questions such as: "How useful is the Family Friendly Study Room?" (1=not useful at all, 5=extremely use$f u l)$, and "Overall, how satisfied are you with your experience with the Family Friendly Study Room?" (1=very dissatisfied, 5=very satisfied). These items were rated on 5-point Likert scales with anchors that matched the dimension being assessed (see the Appendix). To measure participant's opinions about the quality of FFSR specific amenities, participants were asked to rate various aspects of the room on seven items. One question asked: "How would you characterize the quality of the resources provided at the Family Friendly Study Room?". Specific items participants responded to included bathrooms, furniture, children's toys, technology, and location. These items were each scored on 6-point bi-polar rating scales where $1=$ extremely good and $6=$ extremely bad. The items were 
summed to produce a quality scale that evidenced good internal consistency (Cronbach's $\alpha>0.78$ ).

\section{Data Analysis}

Descriptive analyses of the quantitative data were performed using Stata, version 15 (StataCorp, 2017). For the satisfaction items, the data were first checked through frequency tables and scatterplots to identify missing data and potential outliers. There were no outliers. There were missing responses for each of the satisfaction and quality scale questions ranging from two to six missing participant responses. These missing responses were checked to determine that they were missing completely at random. As they were, these missing values were substituted by inserting the average response value of the sample for the items (Jiang et al., 2013). This technique is beneficial as it allows for analysis of scale estimates for the full sample rather than removing all other participant responses from the scale due to a single non-response. However, it is not without its drawbacks as it will underestimate the strength of statistical associations among items. Each item was reversed scored so that higher scores indicated more favorable ratings. A oneway analysis of variance (ANOVA) was performed to check for statistical differences between quality ratings.

Qualitative methods and techniques were used to analyze openended questions. Specifically, all open-ended question responses were reviewed, with no pre-theorized constructs, which allowed themes to emerge. Each response was classified into one or more specific themes. In the case where a participant mentioned more than one theme in their response, it was coded into both themes. Thus, results for the qualitative coding represent the number of mentions as opposed to the number of participants.

\section{RESULTS}

\section{Discovery and Use}

The first discovery question addressed how participants discovered the FFSR. Qualitative analysis of this question revealed three main ways that students learned about the room: (1) through some sort of personal encounter (e.g., seeing a physical sign, walking past the room); (2) through a referral by someone; or (3) through social media. As can be seen in Figure 2, a personal encounter with the room was by far the most 


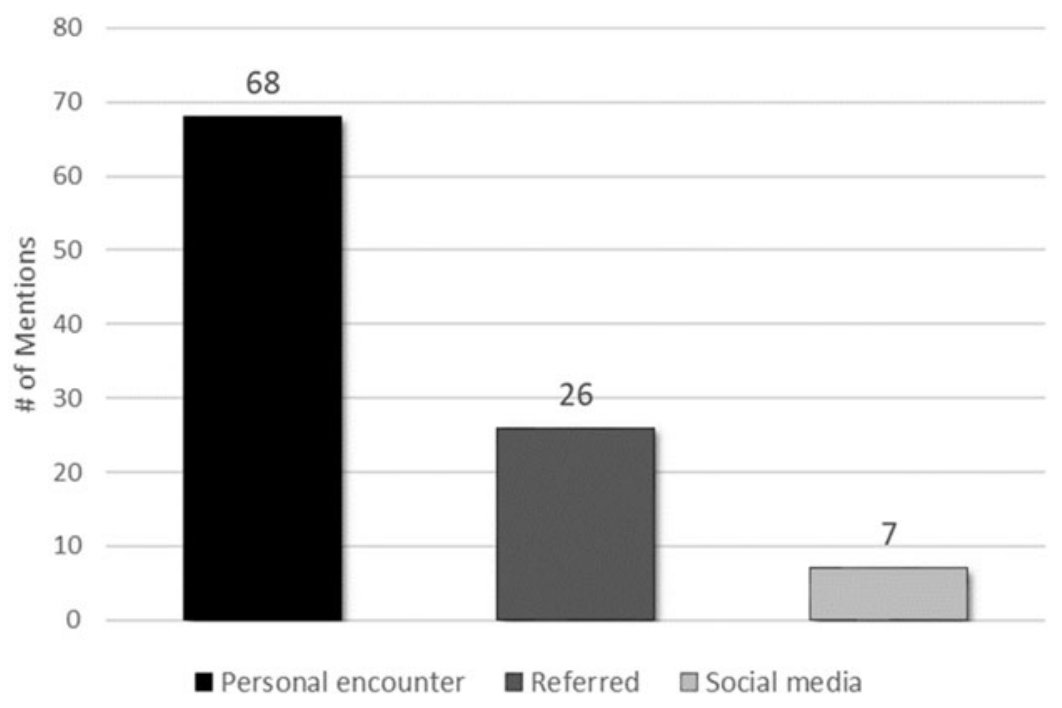

FIGURE 2 Total number times each theme was mentioned in the open-ended responses to the question: "How did you find out about the Family Friendly Study Room." A single answer could include more than one theme.

common way it was discovered. In answer to the question of what participants felt would be the most effective way to inform people about the room, most participants felt that social media and signs would be the optimal platforms, whereas word of mouth and faculty/staff announcements were much less frequently endorsed (see Figure 3). Similarly, when asked the best way to tell people of future rooms or resources at the library, participants recommended social media and signs as the best way to disseminate that information (see Figure 4). It is interesting to note that although the primary way participants learned about the room was by walking past it or seeing a sign, they recommended using social media as the primary means to promote it and other new spaces in the library. Despite their personal exposure experiences, it appears that they underestimated the effectiveness of traditional promotional and discovery methods and recommended advanced technology.

When rank ordering why they used the FFSR, participants endorsed three primary reasons: (1) to parent and study; (2) to trade off parenting with their partner; and (3) to provide their child(ren) a place to play (see Figure 5). Socializing with other parents was their least important reason for using the facility. Survey results also indicated that about one-third of the participants used the FFSR at least once a week (see Figure 6), and almost all participants indicated they were likely to continue using the FFSR in the future (see Figure 7). In fact, there were no students who felt it was unlikely that they would use the room again. Similarly, all participants indicated they were likely to recommend the FFSR to others, and 


\section{0}

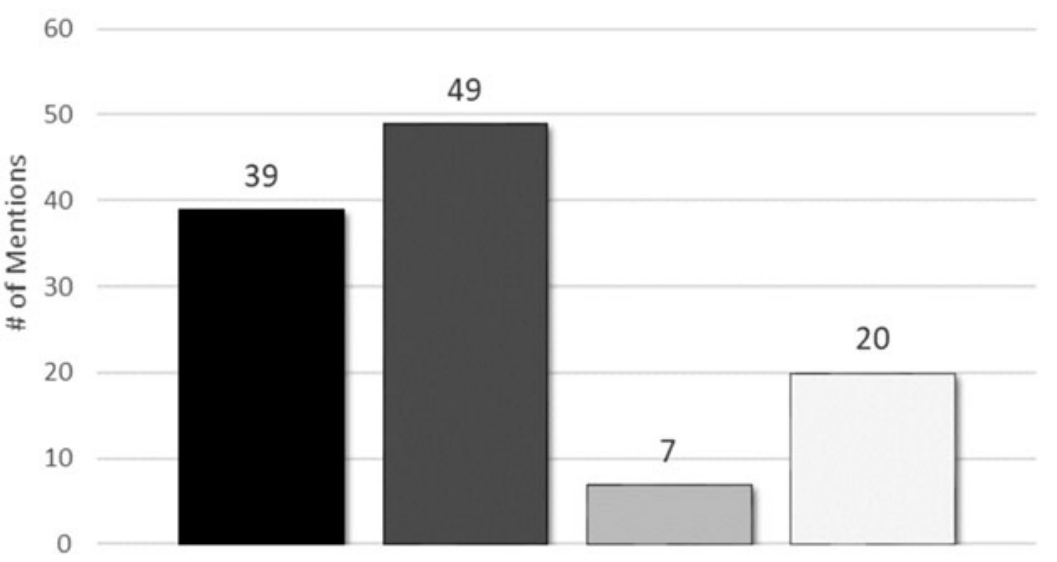

- Signs $\square$ Social media $\square$ Faculty/Staff $\square$ Word of Mouth

FIGURE 3 Total number of times each theme was mentioned in open-ended responses to the question: "What is the best way to inform people at BYU about the availability of the Family Friendly Study Room?" A single answer could include more than one theme.

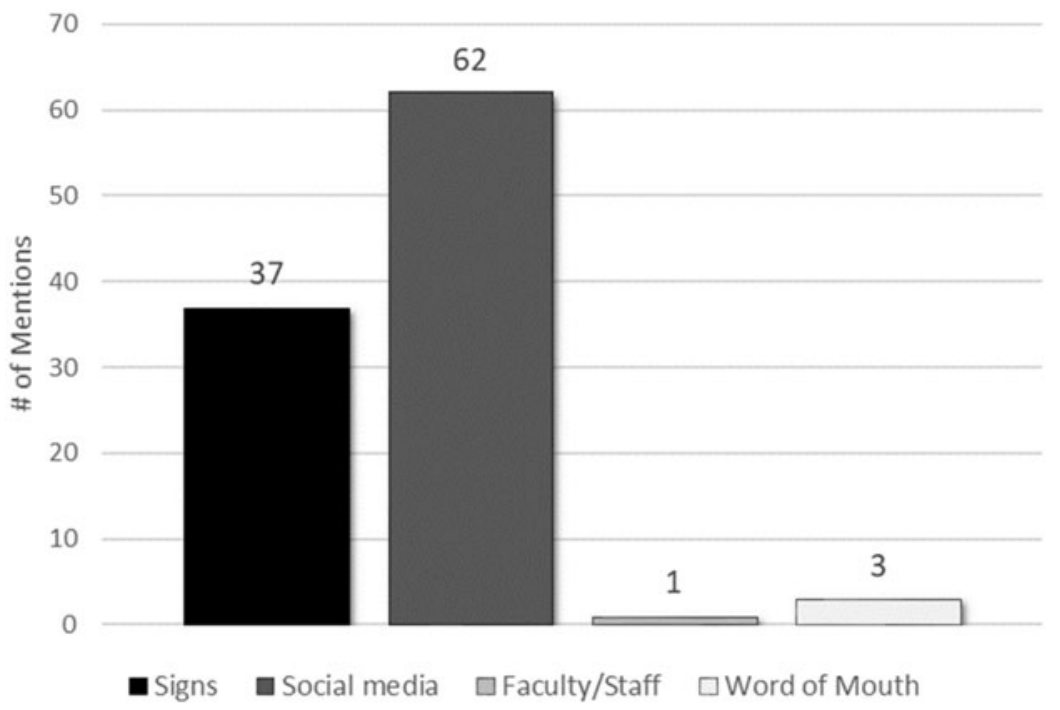

FIGURE 4 Total number of times each theme was mentioned in the open-ended responses to the question: "If the library were to construct other rooms or resources in the future, what would be the best way to tell you about the changes?" A single answer could include more than one theme. 


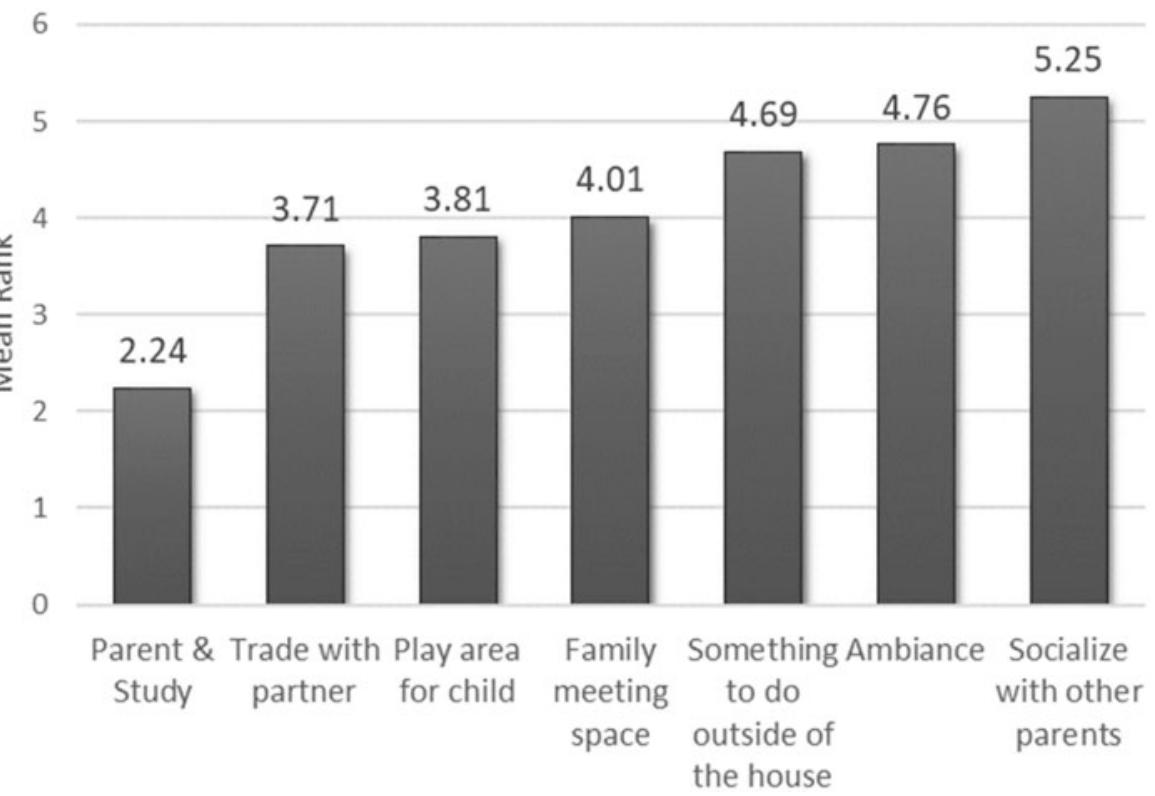

FIGURE 5 Rank ordering of responses to the question: "Please rank the list by order of reasons why you use the Family Friendly Study Room?" ( $1=$ most important reason, therefore lower scores indicate higher importance).

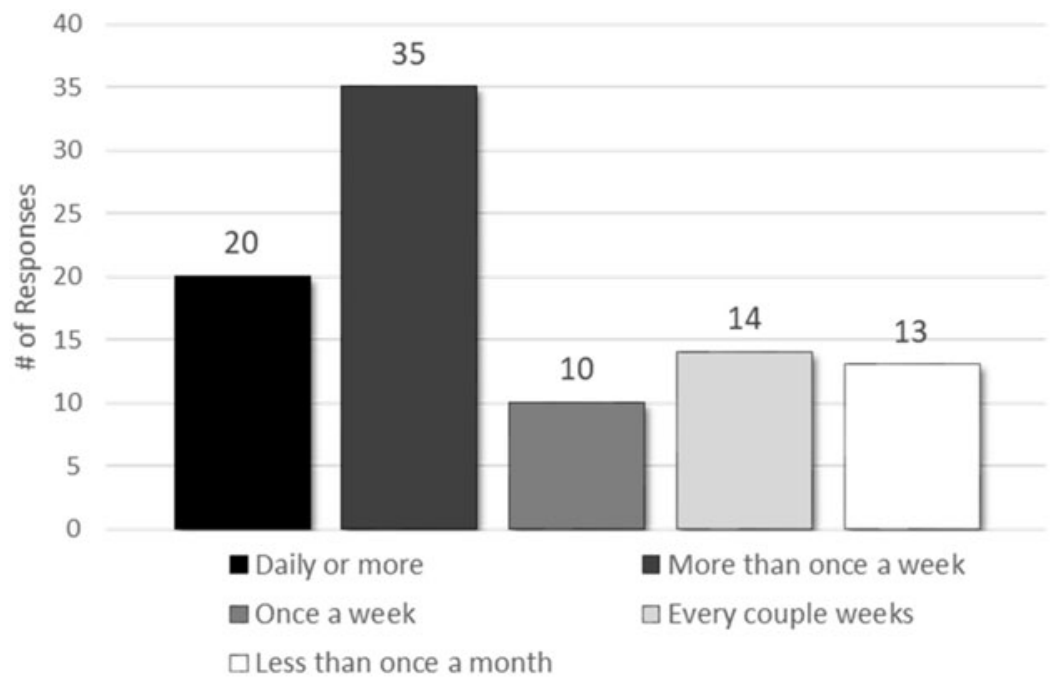

FIGURE 6 Number of responses to the question: "How often do you currently use the Family Friendly Study Room?" 


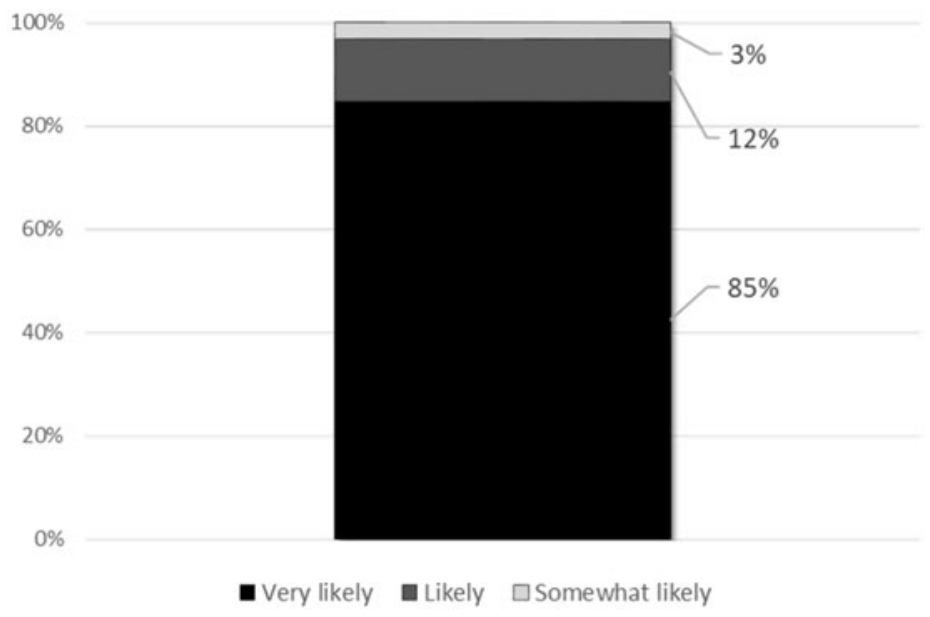

FIGURE 7 Percent of responses to the question: "How likely are you to use the Family Friendly Study Room in the future?" No responses indicated that subjects were "unlikely" or "very unlikely" to use the room in the future.

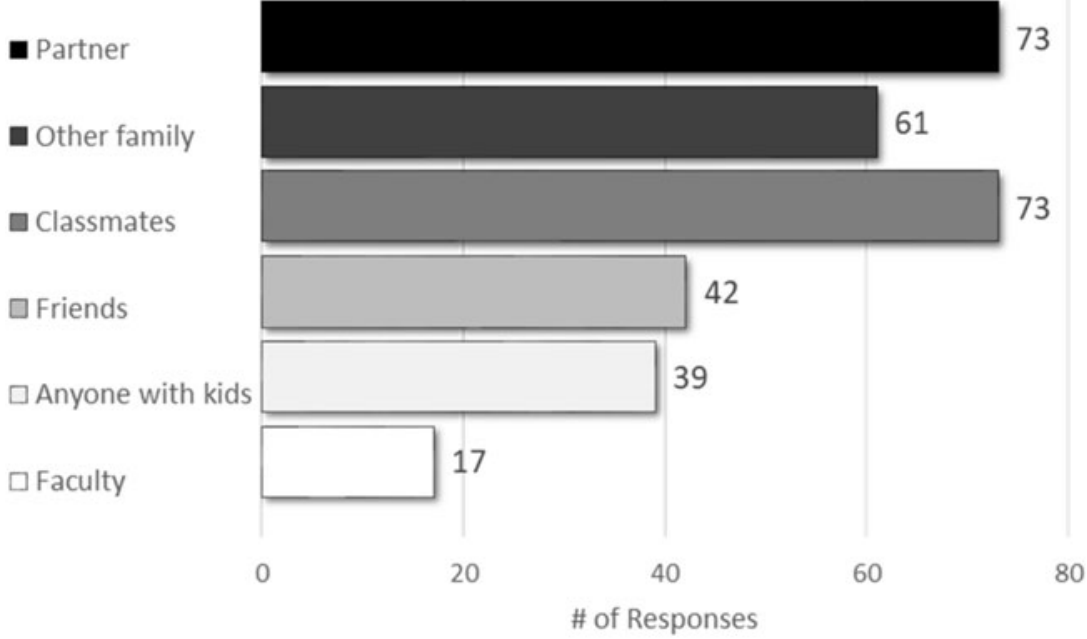

FIGURE 8 Number of responses to the question: "Who have you told about the Family Friendly Study Room? (select all that apply)."

many participants had already told their partners, other family members, and classmates about the room (see Figure 8).

\section{General and Specific Satisfaction}

Overall, participants were satisfied with the various characteristics of the FFSR. Table 2 displays the mean $(M)$ and standard deviation (SD) for each 
TABLE 2 Satisfaction and quality scale ratings of FFSR elements.

\begin{tabular}{lllr}
\hline Satisfaction with FFSR & $N$ & $M$ & $S D$ \\
\hline Useful & 92 & 4.67 & 0.52 \\
Maintained & 92 & 4.16 & 0.75 \\
Sanitation & 92 & 3.96 & 0.78 \\
Safe & 92 & 4.46 & 0.70 \\
Satisfied & 92 & 4.71 & 0.64 \\
Location & 92 & 4.83 & 0.44 \\
Layout & 92 & 4.54 & 0.75 \\
Quality scale items & & & 0.54 \\
Bathroom & 92 & 5.57 & 0.58 \\
Lactation room & 92 & 5.52 & 0.59 \\
Furniture & 92 & 5.62 & 0.52 \\
Study rooms & 92 & 5.67 & 0.71 \\
Computers & 92 & 5.39 & 0.68 \\
Toys & 92 & 5.32 & 0.70 \\
Books & 92 & 5.28 & 2.92 \\
Overall quality scale score & 92 & 38.37 & \\
\hline Note. Satisfacton item & & \\
\hline
\end{tabular}

Note. Satisfaction items range from $1=$ low to $5=$ high. Individual quality scale items range from $1=$ low to $6=$ high. Quality scale total range is $7-42$.

satisfaction question and quality item. The two aspects of the room that were least satisfactory were sanitation $(M=3.96, S D=0.78)$ and maintenance $(M=4.16, S D=0.75)$, although these were still rated highly. The two categories judged to be lowest in quality were toys $(M=5.32, S D=0.68)$ and children's books $(M=5.28, S D=0.70)$. A repeated measures ANOVA revealed significant differences between the quality aspects of the room, $\lambda=0.73, F(6,86)=5.37, p<.001, \eta^{2}=0.27$. To discover which aspects were significantly different, we performed pairwise comparisons between all means. This revealed that the significant differences (with $p s<.002$ using the Bonferroni correction for type 1 error) were between the three highest rated aspects (bathrooms, study rooms, and furniture) and the two lowest rated (toys and children's books). The full quality scale revealed that the majority of participants thought the quality of the FFSR was moderately good or better (see Figure 9).

Participants were also asked to choose their single favorite amenity in the FFSR. The top three responses to this question were the toddler play area (23 responses), the gated infant area (22 responses), and the secluded study rooms (19 responses). The bottom four responses were the computer area (1 response), the children's books/toys (3 responses), the study desks/furniture ( 5 responses), and the family bathrooms ( 9 responses).

Impact on education. A major aim of this study was to assess the impact the FFSR has had on students' education. Participants were asked to freely respond to the question "What impact has the Library's Family Friendly Study Room had on your education?", and 84\% (78 participants) provided a response. These open-ended responses revealed 


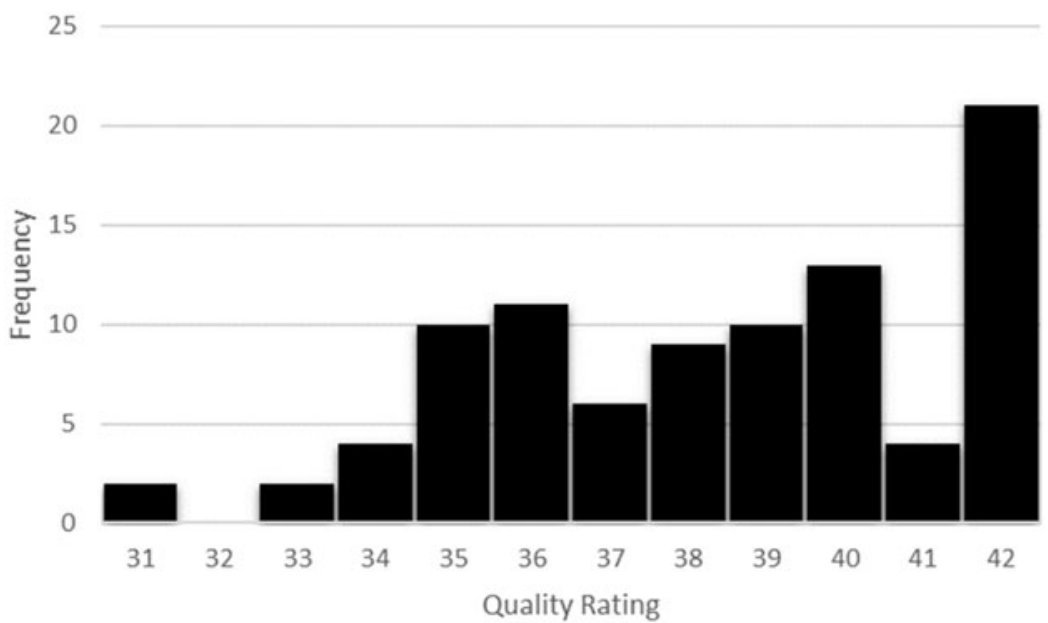

FIGURE 9 Overall quality assessment of the FFSR. Higher scores reflect greater perceived quality (range 7-42).

five common themes, the strongest two which we discuss here (see Table 3 for all five themes). Theme 1 included the majority of responses from participants $(n=44)$ and referenced how the FFSR enabled them to do schoolwork and watch their child without feelings of guilt for disturbing others. For instance, one participant responded: "It has helped because now there is an environment where I can study and not feel like I'm interrupting other students when my baby has needs". The second theme (Theme 2) had the next most mentions (12 responses) and centered around the FFSR being critical to their academic success: "Without it, I would have had to drop out" and "This has been the biggest blessing for my education!".

The next question participants were asked was whether "... the FFSR allowed you to return to school to complete your degree or allowed for you to stay to complete your degree". More than one-third of participants (37\%) answered in the affirmative. Of those participants, each was prompted to elaborate openly, and two themes emerged from these responses. Theme 1 reflected the sentiment that the FFSR was essential to their educational experience (12 responses).

I came back to school while my son was 3 months old. The first 3 days of school, I felt extremely awkward, finding places to sit with my baby and try [sic]to keep him quiet while I waited to go to class. I don't think I would have lasted, it would have been too inconvenient! So this family center has helped TREMENDOUSLY. My baby can cry, and I don't feel like a disturbance! I can nurse my baby, and I don't feel awkward about it! 
TABLE 3 Responses to open-ended questions regarding the educational impact of the FFSR, including coded themes, number of responses, and representative quotes.

\begin{tabular}{|c|c|c|c|}
\hline Theme & Theme topic & $N$ & Quote \\
\hline \multicolumn{4}{|c|}{ What impact has the Library's FFSR had on your education? } \\
\hline 1 & $\begin{array}{l}\text { Allows to work and } \\
\text { simultaneously } \\
\text { watch child }\end{array}$ & 44 & $\begin{array}{l}\text { HUGE! I spend so } \\
\text { much time there } \\
\text { while my baby is } \\
\text { playing ... Our } \\
\text { apartment does not } \\
\text { have the facilities or } \\
\text { opportunities for } \\
\text { interaction to do } \\
\text { this. Not even public } \\
\text { parks are any good } \\
\text { for this because they } \\
\text { don't have fences } \\
\text { and you have to } \\
\text { constantly watch } \\
\text { your child. }\end{array}$ \\
\hline 2 & $\begin{array}{l}\text { Vital to } \\
\text { educational pursuits }\end{array}$ & 12 & $\begin{array}{l}\text { My spouse would have } \\
\text { had to delay ber } \\
\text { graduation until I } \\
\text { was out of school if } \\
\text { I couldn't be doing } \\
\text { bomework E } \\
\text { watching our child }\end{array}$ \\
\hline 3 & $\begin{array}{l}\text { Convenient for } \\
\text { babysitter/trade } \\
\text { with partner }\end{array}$ & 3 & $\begin{array}{l}\text { I have increased bours } \\
\text { studying even while } \\
\text { I watch my baby. } \\
\text { My wife has started } \\
\text { going back to the } \\
\text { gym after dropping } \\
\text { our baby off. }\end{array}$ \\
\hline 4 & $\begin{array}{l}\text { Nonspecific } \\
\text { positive reaction }\end{array}$ & 11 & It's nice. \\
\hline 5 & $\begin{array}{l}\text { No impact/detracted } \\
\text { from education }\end{array}$ & 8 & $\begin{array}{l}\text { Kept me from studying } \\
\text { since I love playing } \\
\text { with my nephew. }\end{array}$ \\
\hline
\end{tabular}

Briefly elaborate how the FFSR has allowed you to return to school to complete your degree or allowed you to be able to stay to complete your degree?

$1 \quad$ FFSR is essential to 12 completing degree

It has been life
changing for me. It
has allowed me to
have a baby and
continue my
education. I don't
know what I would
do without it!
Without my
education would
have been
prolonged by years.

(CONTINUED) 
TABLE 3 Continued.

\begin{tabular}{|c|c|c|c|}
\hline Theme & Theme topic & $N$ & Quote \\
\hline 2 & $\begin{array}{l}\text { FFSR helps make } \\
\text { life easier. }\end{array}$ & 16 & $\begin{array}{l}\text { It has belped because } \\
\text { now there is an } \\
\text { environment where } \\
\text { I can study and not } \\
\text { feel like I'm } \\
\text { interrupting other } \\
\text { students when my } \\
\text { baby has needs. }\end{array}$ \\
\hline
\end{tabular}

Theme 2 suggested that the room generally helped make life easier, including their educational pursuits (16 responses). "I have been able to study while watching my child. It takes a lot of stress off of me".

\section{Participant Recommendations to Improve the FFSR}

Participants were asked what they felt could be improved in the FFSR to help better meet their needs. Although the majority of responses indicated that participants were satisfied and pleased with the space, recommendations for improvements were suggested and coded into two themes. Theme 1 had 52 mentions and addressed changes or additions to the FFSR. Commonly suggested changes/additions included: more private study rooms ("It'd be awesome if there were more secluded study rooms"), a microwave ("Microwaves to heat up bottles and baby food"), a refrigerator ("A breast milk/formula storage fridge..."), an automatic door timing adjustment ("...Far too often someone walks in and a toddler slips out because the door sits open for a while after the person has already walked through"), bathroom mirrors ("I wish there was at least one mirror in each of the bathrooms"), and warm water ("I know this seems like a silly thing, but ... hot water to warm up breastmilk"). Theme 2 centered on maintenance and monitoring room usage and had 15 mentions. Participants suggested the room be periodically cleaned during the day. In addition to general upkeep, participants also mentioned that the room should be monitored for appropriate use (priority be given to those with children) as the room can get crowded during particular times of the day. These suggestions are represented with the following quotes: "The garbage's [sic] are occasionally not changed every day and then the diaper pail smells awful when you open it to put a new diaper in" and "Lots of students without children come and study here because there are typically spots available, and it is annoying when students with kids can't use the amenities because these students are using them." 


\section{DISCUSSION}

One of Ranganathan's five laws of library science is that every reader should be served by his or her book (Ranganathan, 1931). With libraries changing from repositories of learning materials, with quiet study throughout, to a meeting place for active learning and collaboration, Ranganathan's law may need to be updated to: "Every library patron should be served by his or her space." It is our contention that the FFSR created in BYU's library satisfies this "law" by creating a space that serves the needs of a previously underserved group - student-parents. The results of our study demonstrate that the needs of student-parents differ for each family situation and highlight several benefits of family friendly rooms and their amenities. Based on these results, we describe three clear benefits below.

\section{Student-Parent Balance}

The Family Friendly Study Room creates a space where student-parents can find balance in their life as a student and a parent. "This room has facilitated [sic] our every day! It is such an emotional and physical relief to have a place that we can just be parents and students on campus" (survey respondent). Results from this study indicate that the FFSR is a place where parents can engage in family activities (e.g., meet together as a family, allow children to play, do something outside the house), while simultaneously allowing them to study or work on homework assignments. It creates an atmosphere where student-parents do not feel like they are impeding or interfering with the learning of other library patrons. The FFSR is also a place where one parent can pass off parenting duties to another family member, including their spouse. Although it was not the focus of this research, the ability to have children with parents on campus may be an important cost-saving measure, as parents do not need to hire a baby-sitter or use child care services while they are studying.

\section{Educational Effect}

Nearly unanimous feedback from participants indicated that the FFSR was a positive influence on their educational pursuits. Specifically, about onethird of parents (primarily women) indicated that the room enabled them to remain in school to complete their education soon after having children. For many, the FFSR serves as a bridge between the students' life prior to having children and the increased responsibilities after having children and supports them through this transition. It also enables students 
who have left school because of parental responsibilities to return to school to complete their education. In both cases, the FFSR bridges these two worlds and offers support to the student in meeting their academic and family needs.

\section{Emotional Health}

Both of the preceding points converge into the third point, which is that the FFSR can support parents' emotional health. The challenges of completing assignments on time, attending to family duties, working part-time to support a family, and a host of other issues are just some of the unique concerns of student-parents. In these circumstances, the FFSR can become an emotional support room. As described earlier, one student found it to be a place of refuge where she could nurse her newborn and not worry about being a distraction to others. Others found it a convenient way to connect with children between classes, so there was not the feeling of having to choose between neglecting children or neglecting school work. In other cases, student-parents met to exchange parenting duties or, in the case of new mothers, allowed the father to bring the child to the campus to be nursed. In these instances, the FFSR not only became a place for parents to connect with their children, but for spouses to connect with each other. The room appears to have become an important emotional stabilizer to let children and spouses know that they are not lost in the shuffle of academic responsibilities. The FFSR can potentially reduce parents' load by becoming a home away from home, a refuge that removes some of their burdens.

\section{Improving the FFSR}

Whereas there are most likely additional benefits to student-parents, results revealed ways that the FFSR can be improved to better serve the needs of patrons. For example, the ability to heat and cool breastmilk and formula is a desired amenity among many parents. Small children can escape the confines of the room if the door is not engineered to close relatively quickly as people enter and exit the space. Additionally, the space can, at times, become overcrowded. In each of these cases, decisions will have to be made about how to accommodate parents' needs in ways that do not compromise other library priorities. For example, although it is important to be able to regulate the temperature of children's food, the installation of microwave ovens and refrigerators may not be the desired solution. Given open access to the space, it is possible, if not likely, that students without children might choose to heat foods that would emit undesirable odors that could permeate the library (e.g., 
popcorn) or store personal meals in a refrigerator, leaving no room for children's food. The library must also safeguard children with doors that do not open or close so quickly that small ones may be injured. Steps to regulate the number of patrons using the FFSR could be contrary to the administrative policies. This highlights the importance of assessing parental needs and being prepared to develop creative solutions that satisfy the parents, as well as library administration.

Nevertheless, some adjustments are relatively simple to employ to increase parents' satisfaction. Parents suggested that diaper pails be emptied frequently to reduce offensive odors and suggested that mirrors be placed in restrooms. Suggestions such as these are easy to accommodate and do not involve significant cost. The assessment enabled library administration to make swift adjustments to better meet the needs of parents. It also demonstrates the need to engage with students to assess the success of any significant changes to library architecture.

\section{Developing a Family Friendly Room}

Given the results regarding the benefits of a FFSR, this study has shown that they provide a strong argument for universities to adopt Moreau's (2016) third category of active policy making which provides services and spaces that support this student group and their families. In developing these supportive spaces for students (such as a FFSR), there are several considerations in that should be taken into account.

Efforts to identify and create spaces that support student-parents may begin with the identification of student-parent personas and the types of spaces that best suit their needs (Zaugg, 2016; Zaugg \& Ziegenfuss, 2018). Several of these potential personas were described in the introduction of this article. These personas may or may not be part of a university community, but it would be important to identify the members in this group and meet with student-parents to understand how a FFSR would potentially fit into their lives. Some important considerations would include a best location, size, provision of amenities, and policies governing the use of the room. In many cases, this would also involve visiting and evaluating other university libraries with FFSRs. By doing this, BYU was able to design an area that closely matched the needs of its student-parents.

In this instance, visits to FFSRs at the University of Utah and Utah Valley University libraries and a review of local public library programs provided a foundation which were adapted to BYU's specific needs. Once these options were explored, the question then became how the university and the library could implement changes to meet the needs of this 
identified group. In this case, the Lee Library developed spaces and policies that were inviting and inclusive (Moreau, 2016). These changes included locating a FFSR in a prominent, easily accessible area where noise and food are allowed in the library. By design, in order to meet the needs of its specific student-parents, the FFSR included amenities such as a nursing room, a family bathroom, a fenced play space, group study rooms, and other study spaces in an area two to three times the size of other institutions' FFSRs.

\section{CONCLUSION}

While the creation of BYU's FFSR does not claim full success in integrating all diverse groups, the FFSRs implementation has been a step toward creating a welcoming space on the BYU campus for a quickly growing specific group - student-parents. The FFSR offers important accommodations which aid in the academic and familial success for this group. This ongoing assessment has helped identify the degree of successes that implementing a FFSR has had up to this point, and also identify numerous areas for improvement. This assessment has enabled adjustments to serve the needs of its student-parents to ensure that the library fits into their life and supports their dynamic academic endeavors.

\section{ORCID}

Tyler C. Graff (D) http://orcid.org/0000-0003-0838-0442

\section{REFERENCES}

Adam, M. (2014). Student parents struggle to balance college \& children. Hispanic Outlook in Higher Education Magazine, 24(21), 16-18.

Anderson, A. J., Armentrout, M. E., \& Beronä, D. A. (1994). How do you manage? Library Journal, 123(14), 70-71.

Demeules, J., \& Hamer, B. (2013). Retaining young student parents: A growing challenge. About Campus, 18(4), 22-25. doi:10.1002/abc.21127

Godfrey, I., Rutledge, L., Mowdood, A., Reed, J., Bigler, S., \& Soehner, C. (2017). Supporting student retention and success: Including family areas in an academic library. portal: Libraries and the Academy, 17(2), 375-388. doi:10. 1353/pla.2017.0023

Haymond, J. (May, (2018). Family Friendly Study Space. Paper session presented at the Utah Library Association Conference, Provo, Utah. 
Jiang, Y., Terhorst, L., Donovan, H. S., Weimer, J. M., Choi, C.-W. J., Schulz, R., ... Sherwood, P. R. (2013). Locke-Wallace short marital-adjustment test: Psychometric evaluation in caregivers for persons with primary malignant brain tumor. Journal of Nursing Measurement, 21(3), 502-515. doi:10.1891/ 1061-3749.21.3.502

McCoy, R. (2013). Georgia library spotlight-The family room, Collins-Callaway library \& learning resources center, Paine college. Georgia Library Quarterly, $50(4), 1$.

Moreau, M.-P. (2016). Regulating the student body/ies: University policies and student parents. British Educational Research Journal, 42(5), 906-925. doi: 10.1002/berj. 3234

Petit, J. (2014). A family-friendly study room for student-parents and their children at Portland state university library. OLA Quarterly, 20(1), 36-39. doi:10.7710/ 1093-7374.1015

Ranganathan, S. R. (1931). The five laws of library science. London, UK: Edward Goldston.

StataCorp. (2017). Stata Statistical Software: Release 15. College Station, TX: StataCorp LLC.

Tvaruzka, K. (2017). Warning: Children in the library! Welcoming children and families into the academic library. Education Libraries, 32(2), 21-26. doi:10. 26443/el.v32i2.279

Zaugg, H. (2016). Using persona descriptions to inform library space design. In S. S. Hines and K. M. Crowe (Eds.), The Future of Library Space (pp. 335-358). Bingley, UK: Emerald Group Publishing.

Zaugg, H., \& Ziegenfuss, D. H. (2018). Comparison of personas between two academic libraries. Performance Measurement and Metrics, 19(3), 142-152. doi:10.1108/PMM-04-2018-0013

\section{APPENDIX}

Starting this survey implies your consent to participate. Thank you!

Q1.2 Are you willing to participate in this survey?

$\square$ Yes

$\square$ No

Q2.1 How often do you currently use the Family Friendly Study Room?

Daily or more

Once a day

More than once a week

Once a week

Once every couple weeks

$\square$ A few times each semester but less than once a month 
Q2.2 How did you find out about the Family Friendly Study Room? (please be specific)

Q2.3 In your opinion, what is the best way to inform people at BYU about the availability of the Family Friendly Study Room? (be specific in your recommendation[s]).

Q2.4 Please rank (drag and drop) the list below by order of reasons why you use the Family Friendly Study Room? $(1=$ most $)$ Socialize with other parents So my child can play with other children

To trade my child(ren) off with my partner between classes

As a meeting place with my family

For a place to watch my child and study at the same time

For the ambiance

Something to do outside of the house

Other (please explain)

Q2.5 What is your single favorite amenity of the Family Friendly Study Room?
$\square$ Family bathrooms
$\square$ Gated infant area
$\square$ Study desks/furniture
$\square$ Secluded study rooms in the back
Toddler play area
Children's books/toys
Lactation room
Computer area
Other (please explain)

Q2.6 What about the Family Friendly Study Room could be improved to help address your needs better?

Q2.7 How likely are you to use the Family Friendly Study Room in the future?

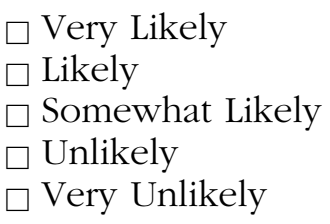

Q2.8 Who have you told about the Family Friendly Study Room? (select all that apply) 
Spouse/significant other

Other family members (siblings, cousins, etc.)

$\square$ Friends who are students

Friends who are not students

Anyone with young kids

Classmates

Faculty/Staff/Teacher

Other (Please specify)

Q2.9 Has the Family Friendly Study Room allowed you to return to school to complete your degree or allowed you to be able to stay to complete your degree?

$\square$ Yes

$\square \mathrm{No}$

Display this Question:

If Has the Family Friendly Study Room allowed you to return to school to complete your degree or all $\ldots=$ Yes

Q2.10 Can you briefly elaborate how the Family Friendly Study Room allowed you to return to school to complete your degree or allowed you to be able to stay at BYU?

Q2.11 How likely are you to recommend the Family Friendly Study Room to others?

Likely

Somewhat likely

Neither likely nor unlikely

Somewhat unlikely

Unlikely

Q2.12 What impact has the Library's Family Friendly Study Room had on your education?

Q2.13 If the library were to construct other rooms or resources in the future, what would be the best way to tell you about the changes?

Q3.1 How useful is the Family Friendly Study Room?

$\square$ Extremely useful

Very useful

Moderately useful

Slightly useful

$\square$ Not useful at all 
Q3.2 How well maintained is the Family Friendly Study Room?

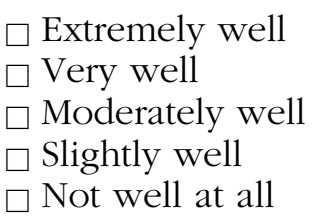

Q3.3 How sanitary do you feel the room (toys, surfaces) is for your child/children?

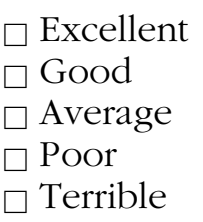

Q3.4 How would you characterize the quality of the following resources provided at the Family Friendly Study Room?

\begin{tabular}{|c|c|c|c|c|c|c|}
\hline & $\begin{array}{l}\text { Extremely } \\
\text { good }\end{array}$ & $\begin{array}{l}\text { Moderately } \\
\text { good }\end{array}$ & $\begin{array}{l}\text { Slightly } \\
\text { good }\end{array}$ & $\begin{array}{l}\text { Slightly } \\
\text { bad }\end{array}$ & $\begin{array}{l}\text { Moderately } \\
\text { bad }\end{array}$ & $\begin{array}{c}\text { Extremely } \\
\text { bad }\end{array}$ \\
\hline Bathrooms & - & - & - & - & - & - \\
\hline Lactation room & - & - & - & - & - & - \\
\hline Furniture & - & - & - & - & - & - \\
\hline $\begin{array}{l}\text { Private study rooms in } \\
\text { the back }\end{array}$ & • & • & • & • & • & • \\
\hline $\begin{array}{l}\text { Computers/printer/ } \\
\text { technology }\end{array}$ & $\bullet$ & • & $\bullet$ & • & $\bullet$ & • \\
\hline Toys & - & - & - & - & - & - \\
\hline Children's Books & • & - & • & - & - & - \\
\hline
\end{tabular}

Q3.5 How much do you like the layout of the Family Friendly Study Room?

Like a great deal

Like somewhat

Neither like nor dislike

$\square$ Dislike somewhat

$\square$ Dislike a great deal

Q3.6 How do you like the location of the Family Friendly Study Room?

Like a great deal

$\square$ Like somewhat

Neither like nor dislike

Dislike somewhat

$\square$ Dislike a great deal 
Q3.7 Currently the mother's lactation room has an open doorway. Would you like:

$\square$ A solid door for privacy and quiet

$\square$ A door with glass for more privacy and quiet

A curtain for privacy

$\square$ I like it the way it is

Other (please specify)

Q3.8 How safe or unsafe do you feel your child/children is/are in Family Friendly Study Room?

Extremely safe

Moderately safe

Slightly safe

Moderately unsafe

Extremely unsafe

Q3.9 Overall, how satisfied are you with your experience with the Family Friendly Study Room?

$\square$ Very Satisfied

$\square$ Satisfied

$\square$ Somewhat Satisfied

Dissatisfied

Very Dissatisfied

Q4.1 What is your gender?

$\square$ Male

$\square$ Female

Q4.2 What is your age (in years)?

$\square$ Under 20

20-23

23-26

26-29

29-32

$\square 32-35$

35-38

$\square 38+$ 
Q4.3 Are you married?

$\square$ Yes

$\square$ No

Display This Question:

If Are you married:=Yes

Q4.4 What is your spouse's age (in years)?
Under 20
$\square$ 20-23
$\square 23-26$
26-29
$29-32$
32-35
35-38
38+

Display This Question:

If Are you married:=No

Q4.5 Are you currently attending BYU?

$\square$ Yes

$\square$ No

Display This Question:

If Are you married: $=$ Yes

Q4.6 Who is attending BYU?

$\square \mathrm{I}$ am attending but my spouse is not

$\square$ Spouse is attending but I am not

$\square$ Both my spouse and I are attending BYU

$\square$ Neither my spouse nor I attend BYU

$\square$ Other (Please explain)

Q4.7 How many children do you have?

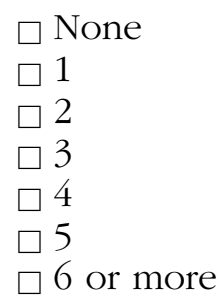


Display This Question:

If How many children do you have?=1

Q4.9 Please indicate the ages of your youngest and oldest children.

\begin{tabular}{lllllll}
\hline & Less than & $2-4$ & $4-6$ & $6-8$ & Older than & $1-2$ \\
& 1 year & years & years & years & 8 years & years \\
\hline Youngest Child & $\bullet$ & $\bullet$ & $\bullet$ & $\bullet$ & $\bullet$ & $\bullet$ \\
Oldest Child & $\bullet$ & $\bullet$ & $\bullet$ & $\bullet$ & $\bullet$ & $\bullet$ \\
\hline
\end{tabular}

Q4.8 What is your child's age?

Less than 1 year

1-2 years

$2-4$ years

$4-6$ years

6-8 years

Older than 8 years

Display This Question:

If What is your current status at BYU?!=Visitor

Q4.11 What college are you associated with?

$\square$ Business

Continuing Education

$\square$ Education

$\square$ Engineering and Technology

$\square$ Family, Home and Social Sciences

$\square$ Fine Arts and Communications

General Studies

Humanities

$\square$ International Studies

$\square$ Law School

$\square$ Life Sciences

Nursing

$\square$ Physical and Mathematical Sciences

Religious Education

Undeclared

Other (please specify)

Q5.1 This is the end of the survey, thank you for completing it. It is only through individuals such as yourself that we are able to evaluate how well we are doing to serve you, so we appreciate your willingness to share your thoughts and opinions with us. Are you interested to be part of the 
drawing to win $\$ 20$ ? If you are, please select 'yes' below to provide your information to be part of the drawing. The answers you provided above will be kept separate from the contact information you provide for the drawing.

$\square$ Yes

$\square$ No

Display this survey:

If ... Are you interested to be part of the drawing? ... =Yes

Q1 You have indicated that you would like to be entered into the drawing to win $\$ 20$ (the odds of winning depend on the number of people who opt into the drawing). Please enter your name and preferred contact information below. Please be assured that your information will not in any way be linked to the survey responses you provided.

Q2 Please enter your first and last name and contact information in the form below.

$\square$ First Name

Last Name

$\square$ Email Address

$\square$ Phone Number

Q3 If you win, how would you prefer to be contacted?

$\square$ Email

$\square$ Text

$\square$ Phone call

Q4 Are you a BYU student?

$\square$ Yes

$\square$ No 